\title{
Educação e violência verbal: o ethos do professor diante desse impasse
}

\section{Cláudia Borragini Abuchaim}

\section{Claudia Rodrigues da Silva Nascimento}

A violência, seja qual for a maneira como se manifesta, é sempre uma derrota.

Jean Paul Sartre

\begin{abstract}
A exposição intensiva a dados violentos relatados pelas diversas mídias, na A contemporaneidade, nos mostra um panorama do terror instaurado em nossa sociedade. A violência ameaça o equilíbrio das instituições nacionais, pois envolve questões sociais, políticas e econômicas.

Este texto se propõe a lançar um olhar sobre a violência verbal em sala de aula. O objeto principal de nosso estudo acercou-se da seguinte reflexão: "Como o ethos do professor se apresenta em situações de violência verbal?". Para a realização desse propósito, constituíram a base analítica a Retórica de
\end{abstract}


Aristóteles ${ }^{1}$, a Nova Retórica de Perelman e Olbrechts-Tyteca ${ }^{2}$ que inspiraram os estudos de Reboul ${ }^{3}$, Meyer ${ }^{4}$, e Ferreira ${ }^{5}$.

Aristóteles, em sua Retórica, reflete sobre a posição do ethos no ato retórico. Mas como podemos perscrutar o ethos do professor?

\section{Ethos: traços de comportamento}

A palavra ética liga-se ao ethos, que para os gregos é a imagem de si, o caráter, a personalidade, os traços de comportamento, a escolha de vida e dos fins. Identifica-se o ethos ao papel do orador porque é alguém que deve ser capaz de responder às perguntas que suscitam debate e que são aquilo sobre o que se negocia. O ethos se liga à pessoa, à imagem que o orador passa de si mesmo, podendo tornar-se exemplar aos olhos do auditório, que poderá segui-lo ou refutá-lo. Afirma-se que o ethos é o orador como princípio (e também como argumento) de autoridade; é o ponto final do questionamento ${ }^{6}$.

Meyer afirma que "o ethos se refere ao pathos e ao logos, atestando valor moral em uma relação com o outro, ou em sua gestão das coisas, mas também no modo de conduzir a própria vida pela escolha dos meios e dos fins ${ }^{7}$."

O ethos (o orador), o pathos (o auditório) e o logos (a linguagem) são igualmente essenciais. Se nada fosse questionável, as pessoas não se comunicariam, portanto, a retórica é a negociação da diferença entre os indivíduos sobre uma questão dada. É a análise dos questionamentos que são feitos na comunicação interpessoal e que as suscitam ou nela se encontram. Negociase pela retórica a identidade e a diferença entre indivíduos, e é desse tema que ela trata, por meio de questões particulares, pontuais, que concretizam sua distância. O insulto, por exemplo, é um procedimento retórico que tem por função assinalar ao outro que não haverá negociação ${ }^{8}$.

Afirma Meyer:

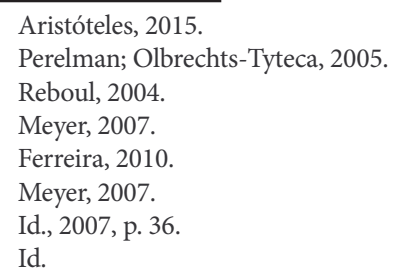


quando a negociamos a partir da questão, do que constitui uma questão, estamos no ad REM (res = "coisa", em latim, portanto, a causa, o que está em causa), e quando o fazemos a partir da intersubjetividade dos protagonistas, estamos no ad hominem, pois nos dirigimos aos homens, ao que eles são, ao que acreditamos que eles sejam, ao que gostaríamos de acreditar que eles fossem, ou ao que recusamos que eles sejam. Todavia, não pode haver uma real separação entre o ad rem e o ad hominem; além disso, frequentemente ofendemos as pessoas, quando não aderimos ao que elas dizem ou propõe, prova de que elas se identificam com o que dizem. Assim sendo, uma boa retórica passa muitas vezes de um plano ao outro, do ad rem ao ad hominem, sobretudo se os argumentos acabam por faltar'.

O ethos está sempre presente como realidade problemática de todo ato retórico, não é dito explicitamente, mas mostrado. O lugar que engendra o ethos é, portanto, o ato retórico, o logos do orador, e esse lugar se mostra apenas mediante as escolhas feitas por ele. É preciso que a credibilidade do orador "seja o efeito do seu discurso"10.

Como explica Aristóteles, no livro I da Retórica:

persuade-se pelo caráter quando o discurso é proferido de tal maneira que deixa a impressão de o orador ser digno de fé. Pois acreditamos mais e bem mais depressa em pessoas honestas, em todas as coisas em geral, mas sobretudo nas de que não há conhecimento exato e que deixam margem para dúvida. É, porém, necessário que esta confiança seja resultado do discurso e não de uma opinião prévia sobre o caráter do orador; pois não se deve considerar sem importância para a persuasão a probidade do que fala, como aliás alguns autores desta arte propõem, mas quase se poderia dizer que o caráter é o principal meio de persuasão ${ }^{11}$.

Retomemos nosso questionamento inicial: "Como o ethos do professor se apresenta em situações de violência verbal?”. Aristóteles afirma

três são as causas que tornam persuasivos os oradores, e a sua importância é tal que por elas nos persuadimos, sem necessidade de demonstrações: são elas a prudência [phrónesis], a virtude

9 Ibid., p.27.

10 Eggs, 2005, p. 30.

11 Aristóteles, 2015, p. 63. 
[areté] e a benevolência [eúnoia]. Quando os oradores recorrem à mentira nas coisas que dizem ou sobre aquelas que dão conselhos, fazem-no por todas essas causas ou por algumas delas. Ou é por falta de prudência que emitem opiniões erradas ou então, embora dando uma opinião correta, não dizem o que pensam por malícia; ou sendo prudentes e honestos não são benevolentes; por isso, é admissível que, embora sabendo eles o que é melhor, não o aconselhem. Para além destas, não há nenhuma outra causa. Forçoso é, pois, que aquele que aparenta possuir todas estas qualidades inspire confiança nos que o ouvem ${ }^{12}$.

O pensamento de Aristóteles nos conduz à hipótese de que a violência verbal ocorra em sala de aula pela perda de credibilidade do orador (professor). Mas como identificar a violência?

\section{Violência}

O vocábulo violência vem do latim violentia, que significa caráter violento ou bravio, força. $\mathrm{O}$ verbo violare significa tratar com violência, profanar, transgredir. O Minidicionário da Língua Portuguesa apresenta o significado de "emprego agressivo e ilegítimo da força ou de processos de coação; força ou poder de uma ação ou de um fenômeno natural"13. A violência se manifesta quando viola os limites impostos pela sociedade.

Afirma Amossy ${ }^{14}$ que traduzir em termos linguísticos o que seja a violência verbal é tarefa difícil. Descreve alguns parâmetros que podem identificá-la, dentre os quais encontramos o uso do insulto, que desqualifica, hostiliza e provoca uma reação daquele a quem se dirige.

A violência em ambiente educacional é uma questão multicausal, complexa, não circunscrita a fatores socioeconômicos. Demanda estudos aprofundados que busquem as causas para melhor compreensão e busca de maneiras eficazes para num futuro próximo erradicá-la de nossa sociedade, e assim, consequentemente, das escolas e universidades. Vários estudos buscam tipificar a violência com o objetivo de implantar políticas públicas para mitigar sua expansão.

12 Ibid., p. 116.

13 Bechara, 2009, p. 910.

14 Amossy, 2017. 


\section{Tipos de violência}

A Organização Mundial de Saúde propôs a divisão da violência em três categorias, segundo as características daqueles que cometem o ato violento: a) violência autodirigida; b) violência interpessoal; c) violência coletiva ${ }^{15}$. A violência verbal em ambiente escolar se enquadra na violência interpessoal, subcategoria violência na comunidade.

Reproduzimos o gráfico de Dahlberg e Krug que ilustra a natureza dos atos violentos, que podem ser: 1) física; 2) sexual; 3) psicológica; 4) relacionada à privação ou ao abandono. A série horizontal na ilustração indica quem é atingido, e a vertical descreve como a vítima é atingida. Esses quatro tipos de atos violentos ocorrem em cada uma das grandes categorias e suas subcategorias descritas acima, com exceção da violência autoinfligida.

\section{Quadro 1 Natureza dos atos violentos ${ }^{16}$}

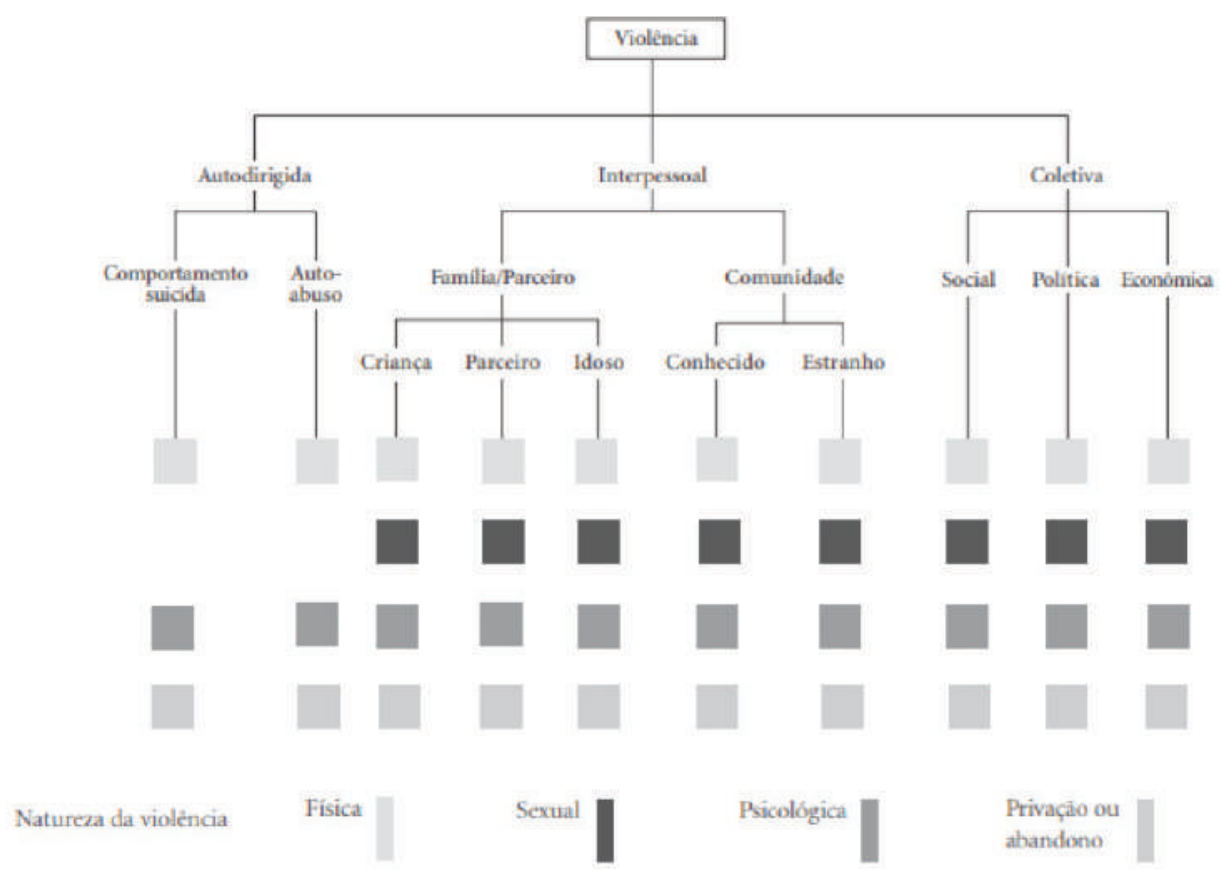

15 WHO, 1996.

16 Dahlberg; Krug, 2007 
No senso comum, a violência é tratada como algo irracional, ora o irracional delimita ausência de razão, mas podemos analisar a violência pelo viés do racional, paradoxalmente, o violento é possuído de uma racionalidade perigosa. As ideologias que legitimam a violência, amplificam os conflitos e reduzem as alternativas de conciliação a um impasse, onde o enfrentamento torna-se a única solução para legitimar a razão.

A violência ocorre de diferentes formas, embora a agressão física seja a mais dramática, as verbais podem se revelar mais perversas, pois atingem o homem no seu próprio ser e deixam marcas indeléveis.

\section{Violência verbal}

Lembremos a célebre expressão de Thomas Hobbes ${ }^{17}$ homo homini lupus ("o homem é lobo para o homem"), base fundamental de sua filosofia política no Leviathan (1651). Freud analisa o pensamento de Hobbes e conclui:

quem se atreveria a refutar este refrão após todas as experiências da vida e da História? Via de regra, esta cruel agressão só espera ser provocada para desencadear-se, quando não se põe a serviço de outros propósitos cujo objetivo poderia ser igualmente alcançado com meios menos violentos. Em condições favoráveis, quando desaparecem as forças psíquicas antagônicas que de forma geral a inibem, ela pode também manifestar-se espontaneamente, desmascarando o homem como besta selvagem que não conhece o menor respeito pelos seres da sua própria espécie ${ }^{18}$.

Freud classifica o homem como "besta selvagem" que desrespeita a própria espécie. A agressividade verbal é uma predisposição para atacar o autoconceito dos outros, pode se interligar com xingamentos, ameaças, chantagens, intimidações, ressentimento e suspeita. De qualquer maneira, a agressão verbal caracteriza uma negatividade destrutiva de comunicação e está intimamente ligada aos problemas das relações sociais. Talvez seja essa uma das explicações de ocorrer cotidianamente em salas de aula.

17 Hobbes, 2003.

18 Freud, 1968, p. 37-38. 


\section{A sala de aula}

O ambiente escolar alicerça-se em turmas de alunos que são tratados erroneamente como coletivo. A estrutura educacional brasileira cobra do professor a matéria dada em sala de aula, automatiza o ensino sem se importar com as idiossincrasias do aluno, o que torna o aprendizado cada vez mais desestimulante ao educando. Prioriza-se o conteúdo em detrimento da relação professor-aluno.

O processo educativo requer acordos prévios de sociabilidade, o professor precisa ouvir o aluno e o aluno também necessita ser ouvido por seus pares. Infelizmente esse princípio básico de convivência não é unanimidade nas práticas educativas. Na sociedade atual, manifesta-se a intolerância, o desrespeito, a apatia que geram a violência verbal e física nas instituições escolares.

Segundo Halliday,

somos seres retóricos: usamos a linguagem como instrumento de mudança ou reforço de percepções, sentimentos, valores, posicionamentos e ações. Quando agimos como seres retóricos, geralmente estamos respondendo aos ditames de uma situaçãa ${ }^{19}$.

A linguagem (logos) é a principal ferramenta do docente, a priori, questão fundamental para interagir com seus alunos em sala de aula. A argumentação que envolve auditórios particulares requer do orador o conhecimento prévio das disposições do auditório (pathos) ao qual se dirige, pois do contrário seu ato retórico poderá ser refutado. É necessário que haja um acordo pré-estabelecido de interação entre professor e aluno.

Reboul afirma

orador, auditório: é impossível que um se dirija ao outro se não houver entre ambos um acordo prévio. De fato, não há diálogo, nem mesmo argumentação, sem um entendimento mínimo entre os interlocutores, entendimento referente tanto aos fatos quanto aos valores. Pode-se dizer, sem paradoxo, que o desacordo só é possível no âmbito de um acordo comum ${ }^{20}$.

19 Halliday, 1988, p. 121.

20 Reboul, 2004, p. 142. 
No Brasil, as salas de aula, do ensino básico às universidades, comportam um auditório heterogêneo nem sempre receptivo aos acordos prévios que se consolidam na dinâmica do aprender. Como afirma Reboul, o desacordo só existe porque algo foi acordado anteriormente. Negando o acordo, o discente resvala para a violência verbal, e o professor, nem sempre preparado para o confronto, pode tornar-se o elo fraco na interação, prejudicando assim, tanto a interação educacional quanto a interação social.

Alguns teóricos, como López Neto, ignoram a realidade escolar de auditórios heterogêneos e a grande dificuldade de comunicação que se estabelece quando a inclusão escolar é feita sem capacitar o professor.

Em um país como o Brasil, onde o incentivo à melhoria da educação de seu povo se tornou um instrumento socializador e de desenvolvimento, onde grande parte das políticas sociais é voltada para a inclusão escolar, as escolas passaram a ser o espaço próprio e mais adequado para a construção coletiva e permanente das condições favoráveis para o pleno exercício da cidadania, pois grande parte das políticas sociais é voltada para a inclusão escolar, passando a escola a ser o espaço propício da construção coletiva e permanente para o exercício da cidadania ${ }^{21}$.

A violência verbal pode nascer da inadequação de um professor (orador) perante uma sala (auditório). Assim como o orador precisa se adaptar a seu auditório, existem auditórios que não se adaptam a determinados oradores.

Nós não escolhemos os nossos alunos (nem eles a nós); porém, na sociedade moderna exige-se que ensinemos a todos eles. Temos que ser eficientes, ensinar a todos, no mesmo ritmo, e trabalhar para que eles aprendam tudo o que o programa determina, no mesmo ritmo ${ }^{22}$.

Questionamos nessa passagem a tarefa que recai sobre o professor: "Podemos ensinar os mesmos conteúdos e no mesmo ritmo a todos os alunos?". Quando o aluno se desinteressa pela aprendizagem desperta paixões no professor nem sempre coerentes com a prática didática. A violência verbal poderá, nesse caso, partir do professor que se sentirá incapaz de ensinar.

O fundamento da autoridade tradicional dos professores, em sala de aula, residiria em seu estatuto intelectual e competência profissional para ensinar, os quais poderiam lhe conferir distinção e uma posição hierárquica superior em relação aos alunos. Mais recentemente, o processo de legitimação da autoridade dos professores passa a destacar o modo como estes interagem

21 López Neto, 2005, p. 170.

22 Mazzotti; Oliveira, 2000. 
com os alunos. Assim, para exercer uma autoridade legítima, os professores precisam demonstrar uma competência para ensinar, bem como competência interpessoal em sala de aula ${ }^{23}$.

Nossa pretensão não é formular um manual de conduta para os docentes, nossa pesquisa propõe algumas reflexões sobre o tema, com o intuito de mostrar aos professores que a busca de soluções para a violência educacional precisa ser ponto crucial para o desenvolvimento didático e pedagógico em ambiente escolar. Como preservar o ethos do professor como mediador de conhecimento nos tempos atuais? Como demonstrar competência intelectual e interpessoal?

Contrapondo-se à necessidade de resgatar no professor o papel de educador, a cobrança para abranger todo o conteúdo programático com carga horária insuficiente, potencializa o distanciamento entre docentes e alunos. Em um estudo reflexivo sobre a violência no ambiente escolar, $\operatorname{Ros}^{24}$ relata que a desmotivação e o desinteresse pelo teor das aulas ministradas associam-se muitas vezes à indisciplina e insatisfação do estudante e podem resultar em comportamento agressivo. Compete ao professor assumir o papel de conciliador e administrar as diferentes situações de agressão verbal com equilíbrio e serenidade. Para que se modifique o panorama de violência no ambiente escolar, educadores e educandos devem desenvolver uma relação de respeito mútuo.

As instituições escolares, microcosmo da sociedade heterogênea, reúnem visões de mundo e de valores éticos antagônicos. Bauman ${ }^{25}$ concebe a expressão "nós e os estranhos" para se referir às diferenças entre os seres que não se encaixam num padrão tido por normal ou desejável em determinada sociedade. Quando o discente passa a ser um "estranho" para o docente, a relação ensino-aprendizagem sofre um abalo que pode reverberar em violência verbal mútua.

Afirmam Perelman e Olbrechts-Tyteca, "os auditórios julgam-se uns aos outros ${ }^{26 "}$. Na dinâmica escolar, o enfrentamento entre professor e aluno pode desaguar numa disputa erística, na qual a racionalidade fugirá do controle, e a retórica da guerra se instaurará não havendo vencedores nem vencidos, apenas "estranhos" que se suportam. O ethos do professor, nessa situação, não condiz com a conduta esperada de um orador que visa persuadir seu auditório, cativá-lo.

De acordo com Ferreira,

23 Garcia, 2009, p. 515-516.

24 Rosa, 2010.

25 Bauman, 1998.

26 Perelman; Olbrechts-Tyteca, 2005, p. 39. 
o ethos possui pelo menos duas faces: uma negativa, que se refere à reserva do território pessoal (nosso corpo, nossa intimidade, nossos pontos fortes ou fracos). Outra positiva, referente à fachada social: uma imagem valorizante, que solicita ao auditório aprovação e reconhecimento. Em muitas esferas específicas de interação, as relações entre orador e auditório são extremamente sensíveis e ameaçadoras à face dos participantes. A distração durante o ato retórico pode contribuir para a não preservação da face e as consequências retóricas são imperativas: ineficácia ${ }^{27}$.

Como afirma Ferreira, a imagem do professor em sala de aula é delineada pela projeção de seu ethos. Na retórica, Aristóteles apresenta dois campos semânticos opostos ligados ao termo ethos: um de sentido moral e fundado na epieíkeia, engloba atitudes e virtudes como honestidade, benevolência ou equidade; outro de sentido neutro ou "objetivo" de héxis, que reúne termos como hábitos, modos e costumes ou caráter. "Essas duas concepções não se excluem, mas, ao contrário, constituem as duas faces necessárias a qualquer atividade argumentativa ${ }^{28}$. .0 orador que mostra em seu ato retórico um caráter honesto parecerá mais digno de crédito aos olhos de seu auditório ${ }^{29}$. Seria a imagem ideal do professor, mas como romper a tensão quando a violência verbal se instaura?

Caberá ao professor encerrar o enfrentamento, como tratamos aqui da violência verbal, encerrar a discussão seria a melhor artimanha retórica. $\mathrm{O}$ ato retórico não pode resvalar para o argumento ad hominem, em que se ataca a pessoa do adversário em vez de atacar sua tese. Mas é necessário possibilitar ao discente acordos posteriores, com retomada de discussões, não de enfrentamentos. Compete ao professor o papel de mediador em sala de aula, jamais de fomentador da violência verbal.

\section{O professor na atualidade}

Meyer afirma que retórica "é a arte de bem falar, de mostrar eloquência diante de um público para o ganhar para a sua causa ${ }^{30 ”}$. O professor dirige-se

\footnotetext{
27 Ferreira, 2010, p. 101.

28 Eggs, 2005, p. 30.

29 Id., 2005.

30 Meyer, 2007, p. 17.
} 
ao aluno com a intenção de ganhar a adesão a seu discurso. Diferente de um orador que pode apenas persuadir pela emoção (movere), o professor ensina, transmite noções intelectuais (docere) e precisa manter a atenção do auditório (delectare), caso contrário não terá o êxito pretendido no ato retórico.

Quem é o professor na atualidade? A lousa e o giz estão ultrapassados, a tecnologia faz parte do cotidiano educacional. Fica difícil imaginar uma sala de aula sem a existência de um projetor multimídia. Os alunos preferem as aulas de leitura com projeções da matéria em telas e já desenvolvem uma certa "preguiça" na hora de escrever, nas universidades, até os cadernos já foram abolidos e os laptops se instalaram nas carteiras. Frequentemente ouvimos o pedido para gravar a aula, assim fica mais "fácil" para estudar em casa. Diante disso, questionamos: o sucesso da aula ainda depende do conhecimento da matéria ou o professor também será avaliado pelo domínio tecnológico que apresenta? A falta de fluência tecnológica cria lacunas entre a interação professor-aluno que pode desencadear em violência verbal?

Percebemos que a violência pode instaurar-se por qualquer motivo ou também pode ser gratuita, como a que tem sido identificada por estudiosos em ambiente educacional, denominada bullying (termo inglês que se refere a uma forma específica de violência).

\section{Bullying}

O bullying foi definido pela Lei no $13.185 / 2015$, que instituiu o Programa de Combate à Intimidação Sistemática como "todo ato de violência física ou psicológica, intencional e repetitivo que ocorre sem motivação evidente, praticado por indivíduo ou grupo, contra uma ou mais pessoas, com o objetivo de intimidá-la ou agredi-la, causando dor e angústia à vítima, em uma relação de desequilíbrio de poder entre as partes envolvidas ${ }^{31}$ ". O dia 7 de abril foi instituído pela Lei ${ }^{\circ} 13.277$, em 2016, como o Dia Nacional de Combate ao Bullying e à Violência nas Escolas ${ }^{32}$.

A gravidade da questão se confirma por meio de estudos recentes como Diagnóstico Participativo da Violência nas Escolas, realizado pela Faculdade Latino-Americana de Ciências Sociais (FLACSO) em 2015, com apoio do

31 Brasil, 2015, on-line.

32 Brasil, 2016. 
MEC, que revelou que $69,7 \%$ dos estudantes declaram ter presenciado alguma situação de violência dentro da escola.

Tognetta e Vinha ${ }^{33}$ apresentam algumas características específicas do bullying: diferentes formas de ridicularização; os atos são sempre direcionados a um alvo, a uma vítima, por repetidas vezes; há a intenção de ferir; diferenças na aparência ou no comportamento são utilizadas para atingir a vítima; há um público que corresponde com as apelações de quem ironiza e age com sarcasmo. Os autores de bullying precisam sentir que lideram os expectadores e propagandeiam seus lamentáveis atos para serem temidos e respeitados.

O bullying é um tipo de violência, na maior parte das vezes verbal, frequente nas escolas e universidades, tanto da rede pública quanto da privada, que provoca baixo rendimento intelectual. Mascarado por brincadeira ou acidente, pode se dar por meio de insulto, apelido pejorativo, gozação, ameaça, perseguição, intimidação, humilhação, acusação injusta, preconceito, hostilização, e desencadear em sua vítima graves consequências psíquicas, como fobias sociais e psicoses ${ }^{34}$.

Combater o bullying não é tarefa solitária, muitas vezes cabe ao professor diagnosticar atitudes que confirmem o bullying, porém são necessárias ações conjuntas envolvendo professores, alunos e seus familiares. $\mathrm{O}$ enfrentamento com quem pratica o bullying é desgastante, na maioria das vezes o agressor nega a violência, e quando confrontado pode inverter a situação e alegar perseguição por parte do professor, que deverá manter um ethos firme, de controle da situação. As instituições educacionais necessitam de professores que se envolvam também nas dinâmicas sociais, que se proponham a conscientizar seus alunos sobre a seriedade e a gravidade dessa prática perversa que se instaurou em nossas escolas, universidades e sociedade.

A abordagem interacional em sala de aula nos permitiu verificar várias manifestações de violência verbal que ocorrem em ambientes educacionais. O ethos do professor em sala de aula é construído diariamente, não apenas manifestado em determinada situação. A identidade profissional do educador precisa se pautar principalmente pelo equilíbrio, pela mediação.

No Livro II da Ética a Nicômaco, Aristóteles nos ensina a ética, mas também a sermos mediadores:

33 Tognetta; Vinha, 2010.

34 Rosa, 2010. 
ora, a excelência moral se relaciona com as emoções e as ações, nas quais o excesso é uma forma de erro, tanto quanto a falta, enquanto o meio termo é louvado como um acerto; ser louvado e estar certo são características da excelência moral. A excelência moral, portanto, é algo como equidistância, pois, como já vimos, seu alvo é o meio termo. Ademais é possível errar de várias maneiras, ao passo que só é possível acertar de uma maneira (também por esta razão é fácil errar e difícil acertar - fácil errar o alvo, e difícil acertar nele); também é por isto que o excesso e a falta são características da deficiência moral, e o meio termo é uma característica da excelência moral, pois a bondade é uma só, mas a maldade é múltipla ${ }^{35}$.

O ethos do professor em situações de violência verbal deverá se pautar pelas "características de excelência moral" como afirma Aristóteles. Persuadir seus alunos por meio da prudência (phrónesis), da virtude (areté) e da benevolência (eúnoia) seria a melhor sugestão para os professores da educação básica até as universidades, assim ensinou o grande mestre da retórica.

35 Aristóteles, 2001, p. 42. 


\section{Referências}

AMOSSY, R. Apologia da Polêmica. Tradução Mônica Magalhães Cavalcante. São Paulo: Contexto, 2017.

ARISTÓTELES. Retórica. Trad. Manuel Alexandre Júnior, Paulo Farmhouse Alberto e Abel do Nascimento Pena. São Paulo: Folha de São Paulo, 2015. (Coleção Folha, grandes nomes do pensamento, 1)

Brasília: UNB, 2001.

Ética a Nicômaco. trad: Mário Gama Kury. 4ªed.

BAUMAN, Z. O mal-estar da pós-modernidade. Tradução de Mauro Gama e Cláudia Martinelli Gama. Rio de Janeiro: Zahar, 1998.

BECHARA, E. Minidicionário da Língua Portuguesa. Rio de Janeiro: Editora Nova Fronteira, 2009.

BRASIL, Ministério da Educação. Lei no 13.185/2015. Acesso em 28 de agosto de 2019. http://portal.mec.gov.br/component/tags/tag/34487

BRASIL, 2016 - Lei no 13.277 - Institui o Dia Nacional de Combate ao Bullying e à Violência nas Escolas. Acesso em 28 de agosto de 2019.

http://www.planalto.gov.br/ccivil_03/_ato2015-2018/2016/lei/L13277.htm

DAHLBERG, L. L.; KRUG, E. G. Violência: um problema global de saúde pública. Ciência \& Saúde Coletiva, 11(Sup): 1163-1178, 2007.

EGGS, E. 2005. Ethos Aristotélico, Convicção e Pragmática Moderna. In: Amossy, R. (Org.) Imagens de si no Discurso: a Construção do Ethos. São Paulo: Contexto: 29-56.

FERREIRA, L. A. Leitura e persuasão: princípios de análise retórica. São Paulo: Contexto, 2010.

FREUD, S. El malestar en la civilización. In: FREUD, S. Obras completas. Madrid: Biblioteca Nueva, 1968. p. 37-38.

GARCIA, J. Indisciplina e violência nas escolas. Diálogo Educacional, Curitiba, v. 9, n. 28, p. 511-523, set./dez. 2009.

HALLIDAY, T. L. Atos retóricos: mensagens estratégicas de políticos e igrejas/Tereza Lúcia Halliday, org. - São Paulo: Summus, 1988.

HOBBES, T. Leviatã ou a matéria, forma e poder de um estado eclesiástico e civil. Trad. Rosina D’Angina. 2. ed. São Paulo: Ícone, 2003.

LÓPEZ NETO, A. A. Bullying: comportamento agressivo entre estudantes. Jornal de Pediatria. Sociedade Brasileira de Pediatria. Rio de Janeiro. Vol 81 No 5, 18. 2005.

MAZZOTTI, T. B.; OLIVEIRA, R. J. Ciência(s) da Educação. 1. ed. Rio de Janeiro: DPA, 2000. v. 1. 158p.

MEYER, M. A retórica. São Paulo: Ática, 2007. 
PERELMAN, C.; OLBRECHTS-TYTECA, L. Tratado da Argumentação. São Paulo: Martins Fontes, 2005.

REBOUL, O. Introdução à Retórica. 2 ed. São Paulo: Martins Fontes, 2004.

ROSA, M. J. A. Violência no ambiente escolar: refletindo sobre as consequências para o processo ensino aprendizagem. Revista Fórum Identidades. Ano 4, Volume 8 | jul-dez de 2010, p.143-158.

TOGNETTA, L. R. P.; VINHA, T. P. Até quando? Bullying na escola que prega a inclusão social. Educação, Santa Maria, v. 35, n. 3, p. 449-464, set./dez. 2010.

WHO - World Health Organization. Global consultation on violence and health.Violence: a public health priority. Geneva: WHO; 1996 (document WHO/EHA/ SPI.POA.2). 
